\title{
Notes on the vocalizations of Eastern Olive Sunbird (Cyanomitra olivacea) and Western Olive Sunbird (Cyanomitra obscura)
}

\section{Peter Boesman}

In the following we briefly analyze and compare voice of Eastern Olive Sunbird (Cyanomitra olivacea) and Western Olive Sunbird (Cyanomitra obscura). We also try to quantify the extent of any vocal differences using the criteria proposed by Tobias et al. (2010), as a support for taxonomic review. We have made use of sound recordings available on-line from Xeno Canto (XC).

Eastern Olive Sunbird: song is a series of staccato notes, ranging from a simple short descending series to a long series with sequences going up and down in pitch. Some examples:

South Africa

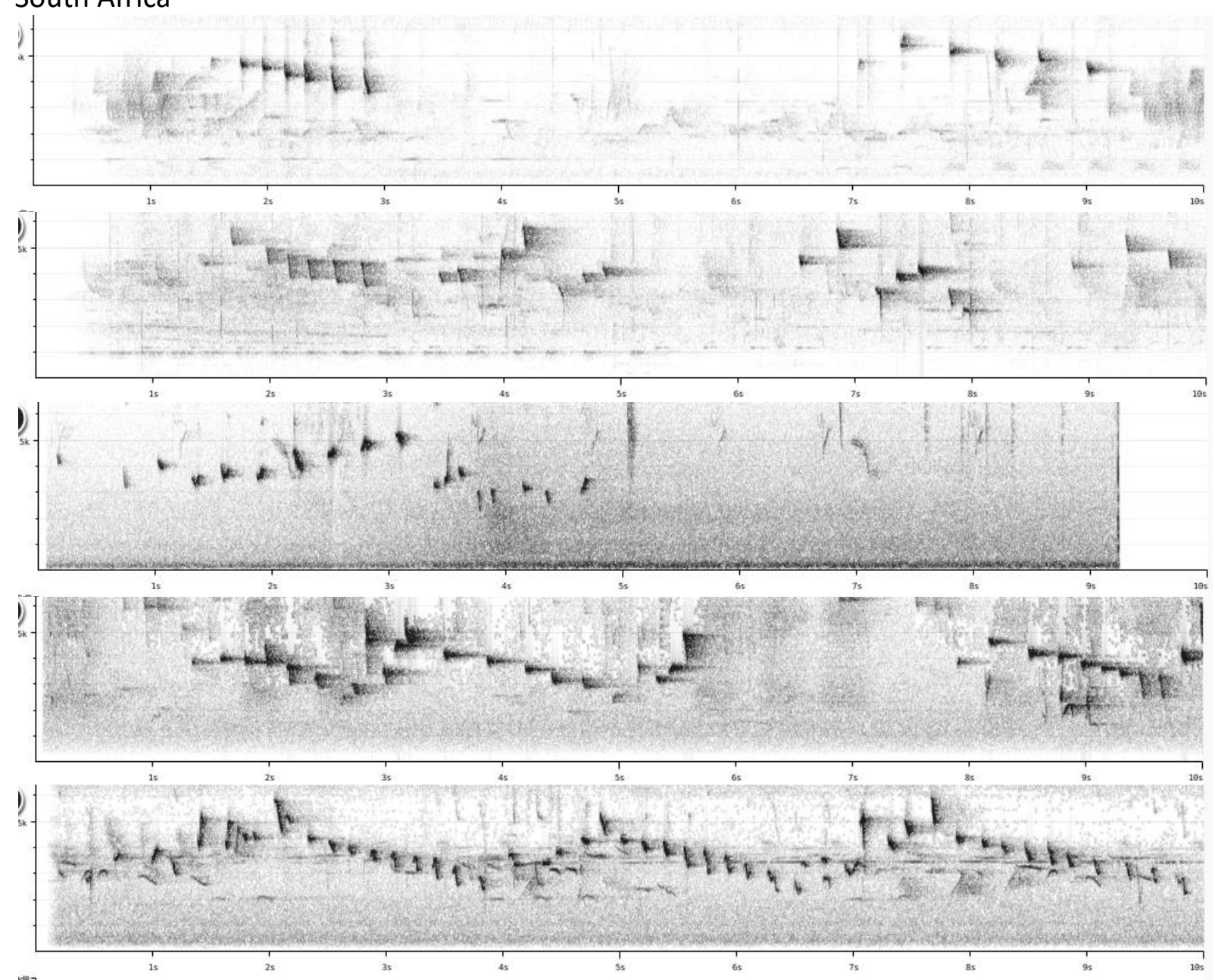




\section{HANDBOOK OF THE \\ BIRDSPFGE WORLD}

\section{ORNITHOLOGICAL NOTES}

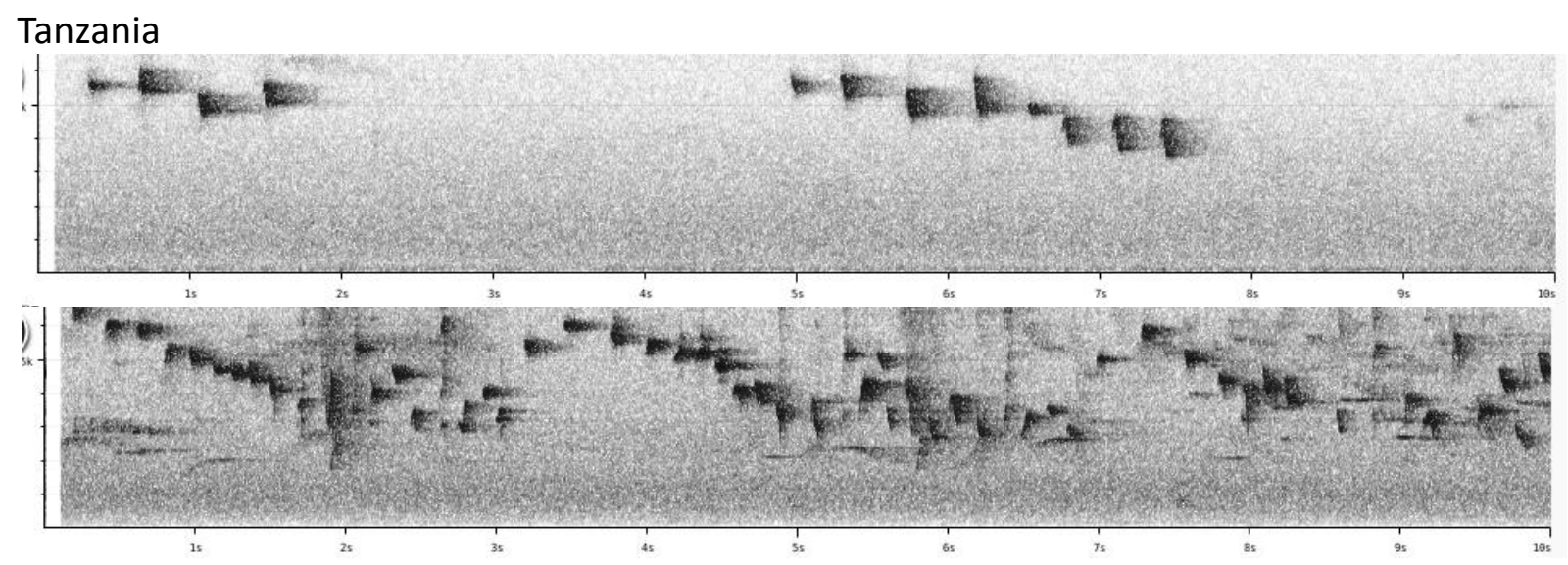

SE Kenya

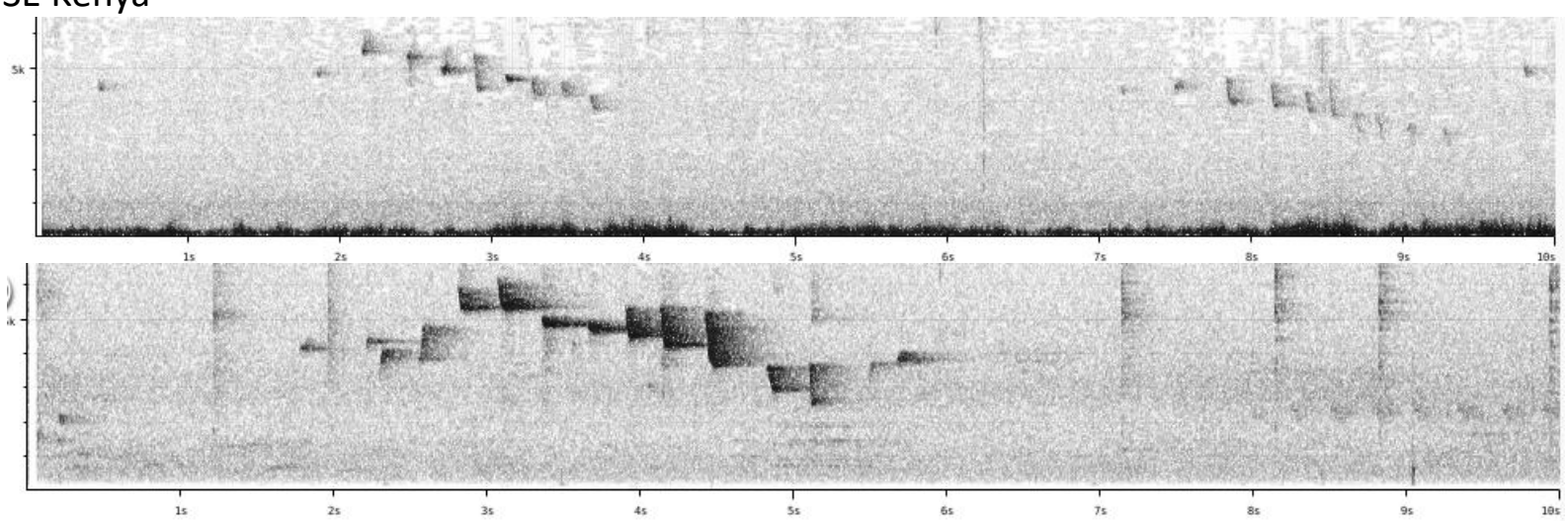

Western Olive Sunbird: song is a series of staccato notes, ranging from a simple short descending series to a long series with up and down sequences. Some examples:

Ghana

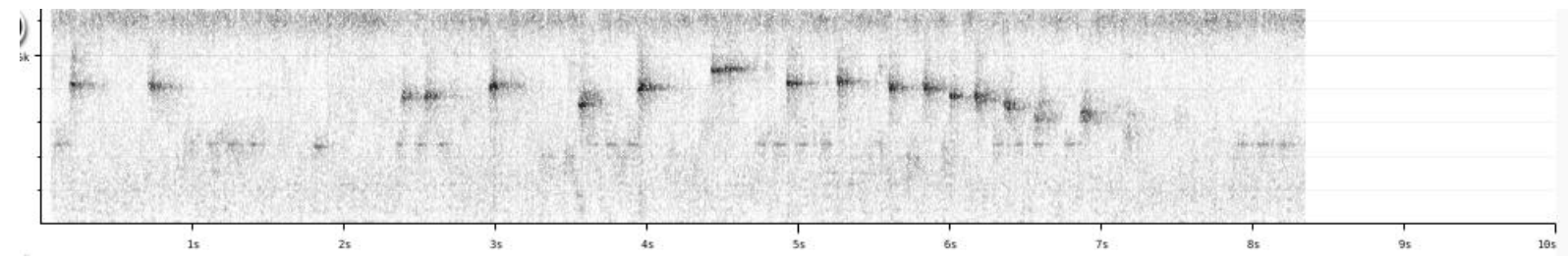

\section{Cameroon}

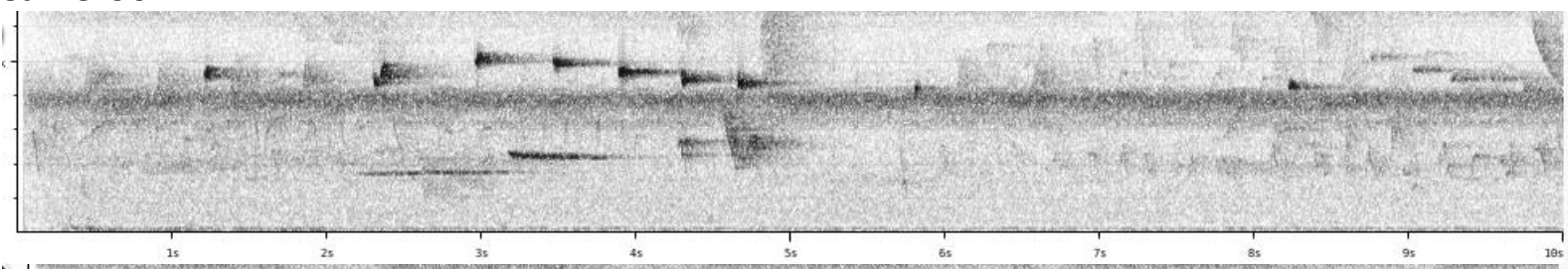

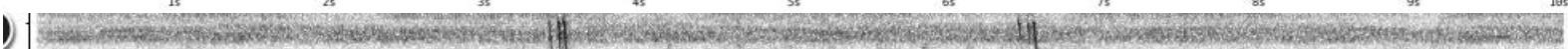

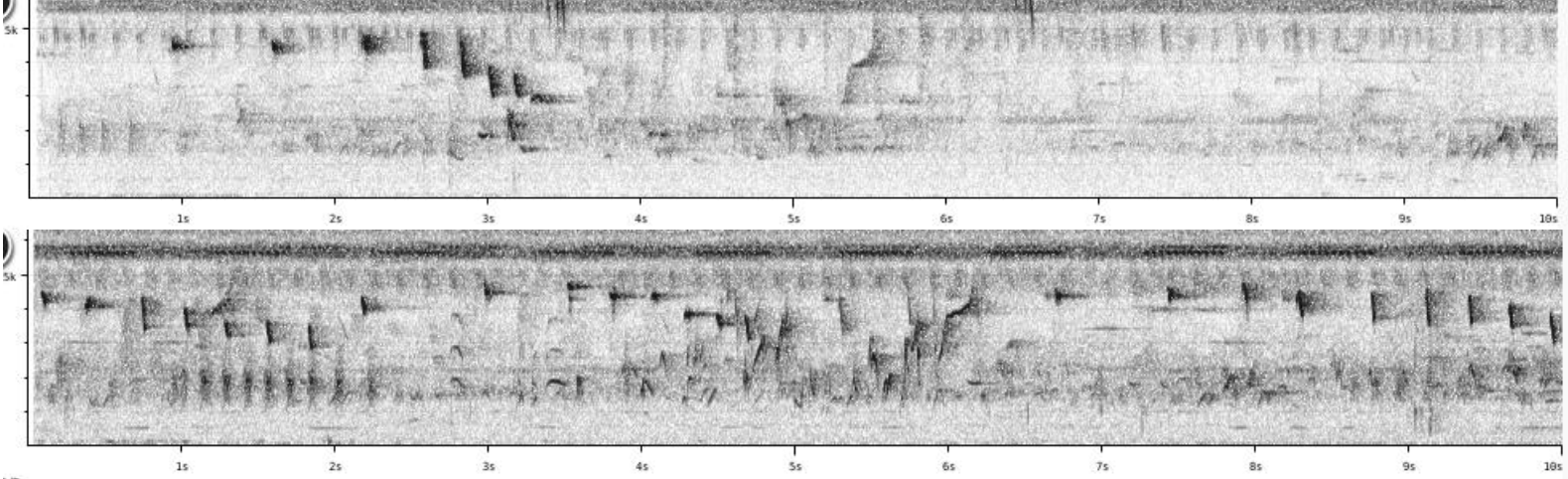



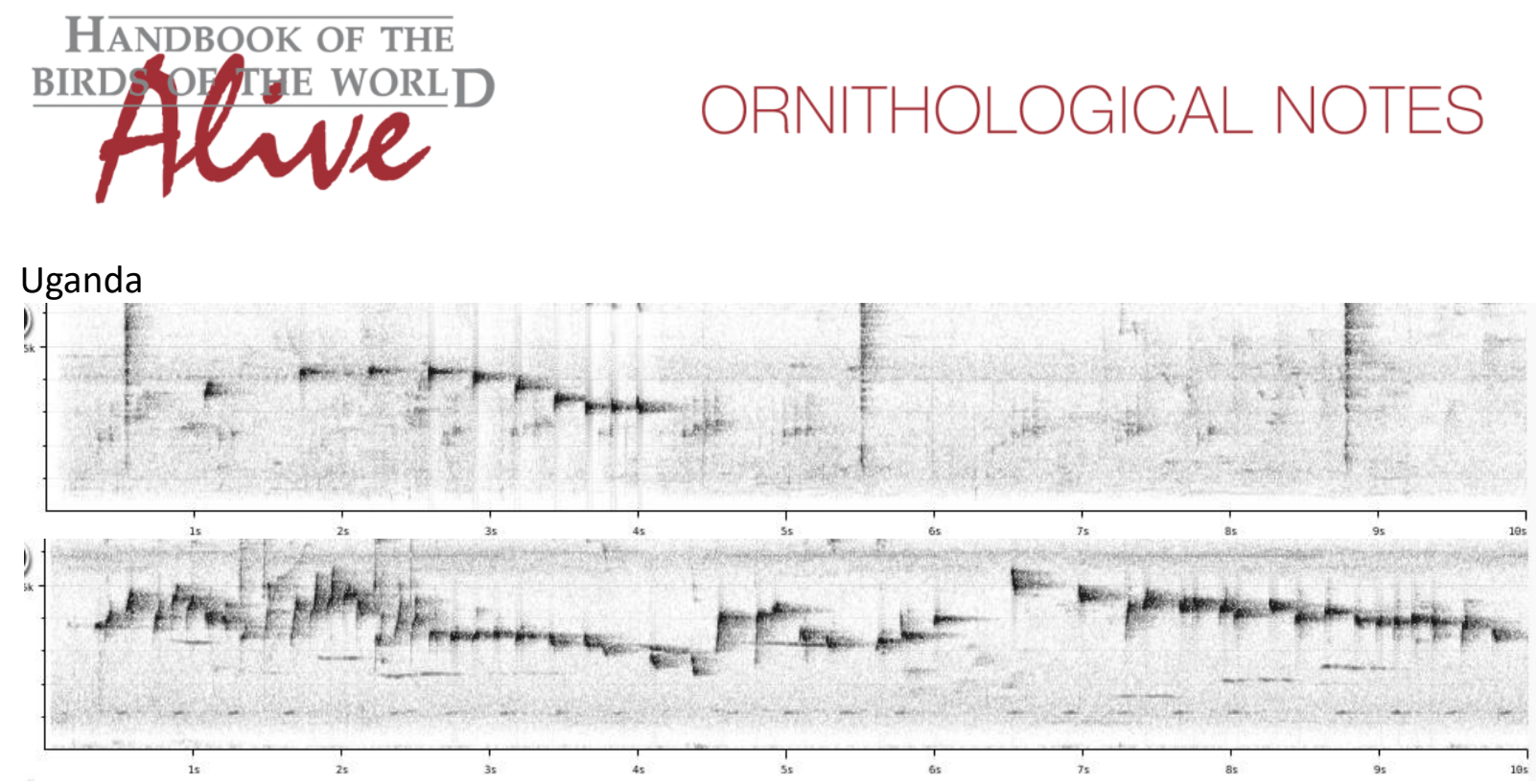

From the above examples, it would seem that song is quite uniform over the entire range of the two groups. At least all basic sound parameters are about equal (note length, \# of notes, $\mathrm{min} / \mathrm{max}$ freq., freq. range...). Even note shapes are very similar.

We can only conclude that there are no obvious vocal differences between both groups. A more in depth study may still reveal slight differences in vocabulary, but in any case, this will not lead to high scores for vocal difference.

This note was finalized on 25th April 2016, using sound recordings available on-line at that moment. We would like to thank in particular the many sound recordists who placed their recordings for this species on XC.

\section{References}

Tobias, J.A., Seddon, N., Spottiswoode, C.N., Pilgrim, J.D., Fishpool, L.D.C. \& Collar, N.J. (2010). Quantitative criteria for species delimitation. Ibis 152(4): 724-746.

\section{Recommended citation}

Boesman, P. (2016). Notes on the vocalizations of Eastern Olive Sunbird (Cyanomitra olivacea) and Western Olive Sunbird (Cyanomitra obscura). HBW Alive Ornithological Note 337. In: Handbook of the Birds of the World Alive. Lynx Edicions, Barcelona. (retrieved from http://www.hbw.com/node/1252796 on 25 October 2016). 